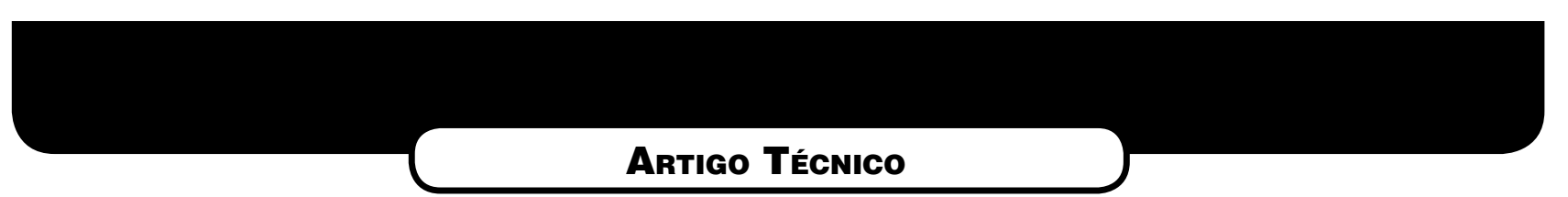

\title{
ESTUDO DO COMPORTAMENTO DE RSU EM UMA CÉLULA EXPERIMENTAL E SUAS CORRELAÇÕES COM ASPECTOS MICROBIOLÓGICOS, FísICOS E QUímICOS
}

\author{
BEHAVIOR STUDY OF MSW IN AN EXPERIMENTAL CELL AND ITS CORRELATIONS \\ WITH MICROBIOLOGICAL, PHYSICAL AND CHEMICAL ASPECTS
}

\begin{abstract}
VERUSCHKa ESCARIÃo DESSOLES MoNTEIRO
Professora do Departamento de Engenharia Civil da Universidade Federal de Campina Grande. Doutora em Engenharia
\end{abstract} Civil (Geotecnia) pela Universidade Federal de Pernambuco (UFPE)

\section{Marcio Camargo de Melo}

Biólogo pela Universidade de Caxias do Sul/RS. Mestre em Engenharia Civil (Geotecnia) pela Universidade Federal de Pernambuco (UFPE). Funcionário da Prefeitura de Caxias do Sul-RS

\section{Perboyre Barbosa de AlCÂNTARa}

Doutorando em Engenharia Civil pela Universidade Federal de Pernambuco (UFPE). Professor do Centro Federal de Educação Tecnológica do Ceará (CEFETCE). Membro do Grupo de Resíduos Sólidos (GRS / UFPE)

\section{JANETE MAGALI DE ARÁUJO}

Professora do Departamento de Antibióticos da Universidade Federal de Pernambuco (UFPE). Doutora em Genética de microrganismos pela Universidade de São Paulo (USP). Membro do Grupo de Resíduos Sólidos (GRS / UFPE)

\section{INGRID RoBERTA DE FRANÇA SOARES ALVES}

Bióloga pela Universidade Federal de Pernambuco (UFPE). Mestranda em Engenharia Civil pela Universidade Federal de Pernambuco (UFPE). Membro do Grupo de Resíduos Sólidos (GRS/UFPE)

\section{José FERNANDo THOMÉ JUCÁ}

Professor do Departamento de Engenharia Civil da Universidade Federal de Pernambuco (UFPE). Doutor pela Universidad Politécnica de Madrid. Coordenador do Grupo de Resíduos Sólidos (GRS) da UFPE

Recebido: 25/05/05 Aceito: 18/07/06

\section{RESUMO}

Células experimentais (lisímetros) possibilitam entender o comportamento de aterros de RSU e representam uma técnica bastante interessante para obter parâmetros de projetos, dimensionamento e construção de aterros, além do mais pode fornecer contribuiçôes na área de saneamento através de monitoramento de processos. O objetivo deste trabalho é avaliar o processo biodegradativo dos resíduos depositados em uma célula experimental correlacionando parâmetros como recalque, temperatura e contagem de microrganismos. O monitoramento mostrou que há uma relação entre estes parâmetros. Verificou-se que a temperatura no lisímetro variou no decorrer do processo possivelmente devido às mudanças de fases de decomposição dos resíduos. Os estudos vislumbram uma nova abordagem para recalques em RSU mostrando a ocorrência de três fazes distintas de deformações verticais e a íntima ligação de processos biodegradativos e aspectos mecânicos.

PALAVRAS-CHAVE: Resíduos Sólidos, Biodegradação, Recalque, Lisímetro.

\begin{abstract}
Experimental cells (lysimeters) make possible to understand the landfill behavior of MSW and represent a very interesting technique for the obtainment of projects parameters, design and constructions of landfills. Besides that, they provide contributions to the sanitation area through processes monitoring. The purpose of this paper is to evaluate the solid waste biodegradation process deposited in an experimental cell correlating parameters like settlement, temperature and microorganisms counting. The monitoring showed that there is a relation between these parameters. It was observed that the temperature in the lysimeter varied in the course of the process, possibly because of the changes in the stages of the solid waste decomposition. The studies descry a new approach to settlements in MSW showing that there are three different stages of vertical deformations and the close connection of biodegradation processes and mechanical aspects.
\end{abstract}

KEYWORDS: Solid Waste, Biodegradation, Settlements, Lysimeter. 


\section{INTRODUÇÃo}

No mundo inteiro, com algumas poucas exceções, os aterros representam a principal destinação final dos resíduos sólidos urbanos (RSU). Em vários países o aterro sanitário tem sido o meio mais importante para se tratar resíduos sólidos de maneira adequada. Neste sentido, vem-se buscando novas técnicas para aprimorar a disposição e o tratamento destes resíduos. As técnicas de tratamento estão cada vez mais interligadas a aspectos geotécnicos e biotecnológicos. No intuito de conhecer melhor o funcionamento de aterros de RSU, células experimentais representam uma técnica bastante interessante, pois permitem obter parâmetros para projetos, dimensionamento, construção e monitoramento de aterros. Além disso, normas técnicas que hoje são muitas vezes inadequadas podem ser reformuladas ou aprimoradas a partir dos estudos desenvolvidos em células experimentais como os lisímetros. Nesta nova concepção pode-se ainda monitorar mais facilmente fases de degradação dos resíduos e até compreender melhor rotas metabólicas de degradação de produtos orgânicos, uma vez que fica mais fácil conhecer e controlar as condiçôes do meio.

Os Biorreatores (lisímetros) otimizam as condiçôes para decomposição microbiológica e aceleram a estabilização da massa de lixo permitindo a disposição adicional de RSU ou reuso mais rápido do aterro. São projetados geralmente para que a água de infiltração da chuva nos resíduos seja feita sob condiçôes controladas. A gerência adequada destes parâmetros pode levar a estabilização muito rápida dos resíduos e a ritmos de alta produção de metano (Borglin et al, 2004).

O objetivo deste trabalho é avaliar o processo biodegradativo dos resíduos depositados em uma célula experimental (lisímetro) correlacionando parâmetros como recalque, temperatura e contagem de microrganismos. A célula experimental foi construída no Aterro da Muribeca localizado na Região Metropolitana do Recife (RMR).

\section{METODOLOGIA}

O trabalho foi desenvolvido com as seguintes etapas:

- Construção da célula experimental (Figura 1);
- Instrumentação: piezômetro; termopar; medidor de recalque superficial (2 placas); medidor de recalque em profundidade (discos magnéticos); dreno de gás e estação meteorológica no Aterro da Muribeca. Os termopares estão posicionados nas profundidades $(0,05 ; 0,50 ; 1,00 ; 1,75,2,00 ; 2,50 \mathrm{~m})$ conforme indicado na Figura 1. As temperaturas foram medidas durante 7 meses de monitoramento nestas profundidades;

- Caracterização física, química e microbiológica dos resíduos. A coleta de amostras para análise da composição gravimétrica, composição química, parâmetros físico-químicos e microbiológicos foi feita de acordo com IPT/CEMPRE (2000); CETESB (1990) e Palmisano et al (1993).

- Preenchimento da célula: amostragem: resíduos que chegam ao aterro da Muribeca provenientes de 3 rotas da RMR que atendem a setores de diferentes classes sociais (bairros de classe alta, média e baixa); preenchimento: resíduos devidamente homogeneizados e compactados em camadas com a densidade de aterros sanitários;

- Monitoramento: Líquidos: geração de lixiviado; fases: hidrólise; acidogênese; acetogênese; metanogênese; Sólidos: comportamento da massa de resíduos; fases: hidrólise; acidogênese; acetogênese; metanogênese; Gases: geração (fases); geração associada a composição química; composição do biogás.

A célula experimental foi construída em alvenaria com seção transversal circular de 2,0m de diâmetro e um volume total aproximado de $11 \mathrm{~m}^{3}$ (Figura 1). A célula conta com uma camada de base e cobertura de argila compactada na umidade ótima com energia do proctor normal. Foi empregado o mesmo solo utilizado na cobertura das células do aterro da Muribeca.

O monitoramento no lisímetro é realizado com o objetivo de analisar aspectos geotécnicos e a evolução do processo degradativo da matéria orgânica ao longo do tempo e profundidade. Os dados foram obtidos através da instrumentação instalada e da coleta de amostras de lixo para análise em laboratório. Sistematicamente são coletadas amostras de líquidos, sólidos e gases para determinação de parâmetros físicoquímicos e microbiológicos como: $\mathrm{pH}$, DBO, DQO, amônia, metais, umidade, sólidos voláteis, proteínas, celulose, lignina, concentração de metano, dióxido de carbono e ainda a quantificação de fungos, bactérias aeróbias, anaeróbias, proteolíticos, celulolíticos, amilolíticos e testes de fitotoxicidade (Apha, 2002; Who, 1979; Palmisano et al, 1993). Para coleta das amostras de anaeróbios, foi utilizada uma jarra de anaerobiose (Gaspak), com finalidade de impedir a troca de oxigênio das amostras com o meio ambiente.

As amostras de lixo são obtidas com auxílio de um amostrador do tipo Shelby, cravado por percussão, através de aberturas laterais na parede do lisímetro. Para isso foram instalados 15 tubos nas profundidades P1, P2, P3, P4 e P5 como ilustra a Figura 1. Em cada profundidade estão distribuídos, uniformemente, três tubos. Em cada coleta foram formadas duas amostras: a primeira com o lixo coletado nas profundidade P1 e P2, representando a parte superior da célula e a outra proveniente das profundidade $\mathrm{P} 3, \mathrm{P} 4$ e P5, na parte inferior. Para análise dos resultados serão consideradas as faixas superior (amostras $\mathrm{P} 1+\mathrm{P} 2$ ) e inferior (amostras $\mathrm{P} 3+\mathrm{P} 4+\mathrm{P} 5)$ do lisímetro.

Para a realização das análises microbiológicas para quantificação de microrganismos aeróbios e anaeróbios totais, celulolíticos, amilolíticos e proteolíticos foi utilizada a seguinte metodologia (Alves, 2005):

- Para quantificação de microrganismos aeróbios utilizou-se, inicialmente, $10 \mathrm{~g}$ da amostra de resíduos sólidos provenientes do lisímetro. Foram diluídas em Erlenmeyer de $125 \mathrm{ml}$, contendo $90 \mathrm{ml}$ de solução tampão fosfato. A mistura foi submetida a 15 minutos de agitação na mesa agitadora e, em seguida, foram realizadas diluições decimais de $10^{-1}$ a $10^{-8}$. Em tubos de ensaio contendo meios de cultura específicos (Palmisano et al, 1993, modificado neste trabalho) para cada grupo: celulolíticos, proteolíticos e amilolíticos foram inoculados volume de $10 \mathrm{ml}, 1 \mathrm{ml}$ e $0,1 \mathrm{ml}$ das diluiçôes. Foi utilizada a técnica dos tubos múltiplos (Série de 3 tubos), de acordo Apha (2002) para cada grupo microbiano e assim determinado o número mais provável (NMP) desses microrganismos através da Tabela de Hoskins. Após a inoculação, os tubos foram levados à estufa a $37^{\circ} \mathrm{C}$ durante 12 dias.

- A quantificação de microrganismos anaeróbios foi realizada da seguinte forma: inicialmente, para 
liberar os microrganismos aderidos aos resíduos, $10 \mathrm{~g}$ da amostra foi diluída em Erlenmeyer de $125 \mathrm{ml}$, contendo $90 \mathrm{ml}$ de solução tampão redutor. A mistura foi submetida a 5 minutos de suave agitação manual e, em seguida, foram realizadas diluiçóes decimais de $10^{-1}$ a $10^{-10}$. Em tubos de penicilina com meios de cultura específicos (Palmisano et al, 1993, modificado neste trabalho) para cada grupo: anaeróbios totais, celulolíticos, proteolíticos e amilolíticos foram previamente selados para evitar a troca de oxigênio com o meio ambiente e inoculados com $1 \mathrm{ml}, 0,1 \mathrm{ml}$ e $0,01 \mathrm{ml}$ da amostra diluída. O oxigênio contido no meio para anaeróbios totais foi retirado e insuflando nitrogênio. A técnica dos tubos múltiplos (Série de 3 tubos), de acordo com o FOOD AND DRUG ADMINISTRATION (1984), foi utilizada para cada grupo microbiano e assim o número mais provável (NMP) desses grupos microbianos foi quantificado através da Tabela de Hoskins. Após a inoculação, os tubos foram levados à estufa a $37^{\circ} \mathrm{C}$ durante 12 dias.

\section{RESULTADOS E DISCUSSÃO}

\section{Composição gravimétrica dos resíduos}

Os resíduos sólidos destinados ao enchimento do lisímetro passaram por um detalhado processo de separação dos seus constituintes. $\mathrm{O}$ objetivo desta separação é entender o processo degradativo e prever o tempo de degradação dos compostos presentes na massa de lixo.
Na Figura 2 são mostrados os resultados da composição gravimétrica dos resíduos obtida antes do enchimento do lisímetro e uma descrição detalhada dos tipos de plásticos encontrados. Para se entender o tempo de degradação de cada um dos componentes plásticos, estudos mais elaborados estão sendo desenvolvidos a fim de prever o seu grau de degradabilidade e como estes compostos interferem no processo degradativo como um todo.

No material presente na composição gravimétrica verifica-se um maior percentual de material orgânico seguido de plásticos, vidros e outros constituintes em menores quantidades. Este percentual de material orgânico $(45,5 \%)$ foi baixo se comparado àquele disposto em aterros de RSU. Ainda é importante ressaltar que o percentual de umidade dos resíduos verificado durante a caracterização inicial foi de aproximadamente $52 \%$, um valor dentro da normalidade para as condiçôes brasileiras. Embora segundo Palmisano \& Barlaz (1996), esta umidade seja relativamente elevada para processos biodegradativos, isto deve-se a presença de precipitação durante o enchimento do lisímetro e pode determinar um ambiente propício para microrganismos aeróbios, devido a difusão de oxigênio dissolvido na água podendo ainda acelerar o processo inicial de biodegradação.

Pode-se destacar a grande quantidade de plásticos encontrados no material utilizado para o enchimento do lisímetro. Isso pode estar relacionado à grande quantidade de sacolas plásticas e embalagens diversas presentes no lixo. Destaca-se a grande quantidade de materiais do tipo polietileno de alta e baixa densidade, além de polipropileno, que são largamente utilizados nas embalagens plásticas.

Segundo o IPT/CEMPRE (2000) uma quantidade excessiva de material plástico em aterros ou lixóes pode provocar a queima indevida e sem controle bem como dificultar a compactação do lixo. A disposição de plásticos pode ainda prejudicar a decomposição dos materiais biologicamente degradáveis uma vez que afetam as trocas de líquidos e gases gerados nos processos de biodegradativos de aterros de RSU. No lisímetro a quantidade de plásticos e derivados foi considerada alta, entretanto não houve problemas relacionados com a compactação do lixo, já que a densidade foi de 0,6 ton $/ \mathrm{m}^{3}$ que é considerada uma boa densidade para uma compactação manual em uma célula experimental, além de ser a densidade encontrada em diversos aterros de RSU. Quanto a aspectos biodegradativos, pode-se dizer que até o momento não houve interferência da quantidade de plásticos no processo de degradação, pois os resíduos encontram-se nas fases iniciais e de uma maneira geral o plástico não é um material biodegradável. Contudo, vale ressaltar que já existem materiais poliméricos biodegradáveis que possuem um aditivo incorporado ao PEAD encontrado principalmente em embalagens plásticas que expostas ao ambiente, após descartadas, é rapidamente eliminada pelos microrganismos atuantes durante o processo de degradação. Estes materiais poderiam inclusive
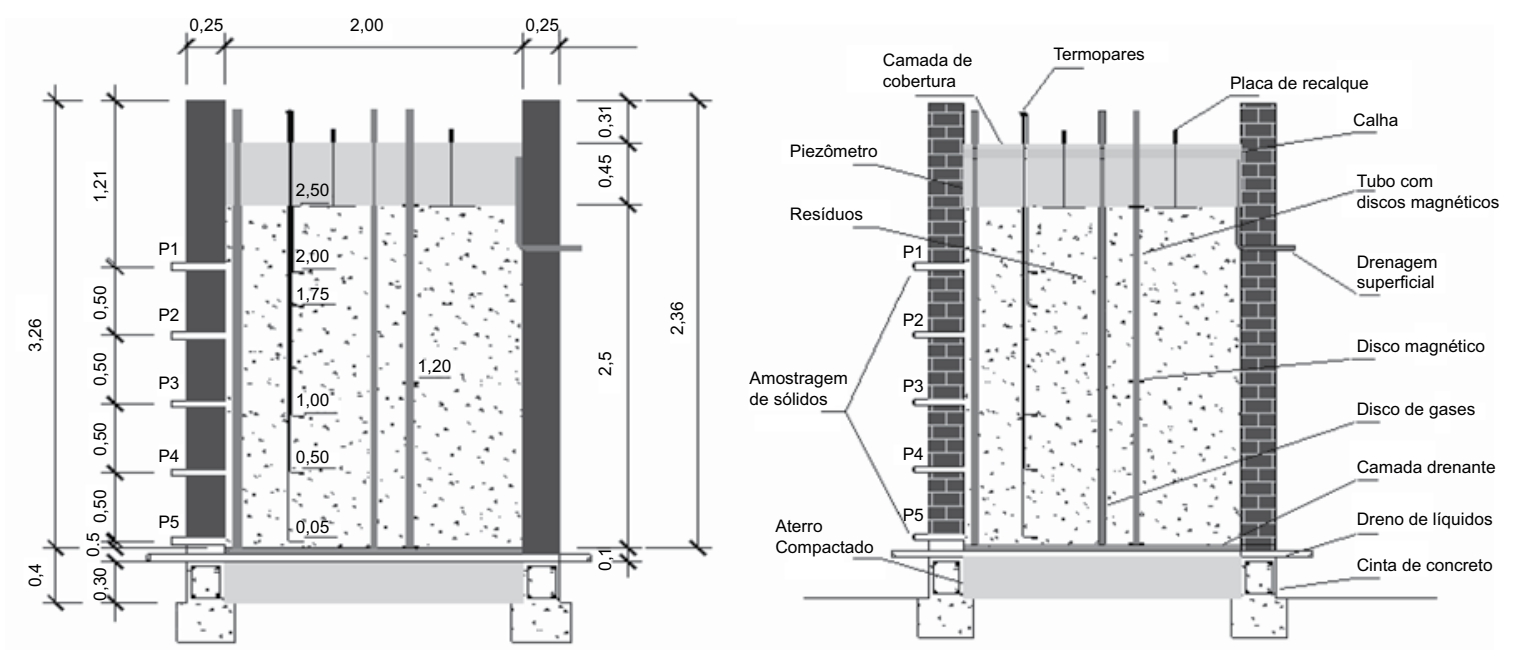

Figura I - Desenho esquemático da célula experimental (lisímetro) 
no futuro próximo reduzir problemas ambientais, operacionais e biodegradativos caso fossem depositados em aterros em substituição ao material plástico atualmente utilizado.

\section{Biodegradação e aspectos correlacionados}

A degradação inicial dos resíduos por microrganismos permite a transformação dos compostos complexos em subprodutos menos complexos. Tais compostos irão ser novamente quebrados por outros grupos de microrganismos presentes na massa de lixo até a formação final de $\mathrm{CH}_{4}, \mathrm{CO}_{2} \mathrm{e}$ $\mathrm{H}_{2} \mathrm{O}$. Esta transformação de compostos complexos a compostos simples permite a redução da massa de lixo. Entretanto, estes mecanismos bem como aspectos relacionados à biodegradação não estão totalmente entendidos. Portanto, estudos em células experimentais têm sido uma das justificativas para o melhor entendimento do comportamento de aterros devido à facilidade de conhecimento e controle das condições internas e de contorno. Vale salientar que muito dos conhecimentos atuais sobre o comportamento de aterros foi conseguido através de estudos em células experimentais. Esta análise é baseada no monitoramento de diversos parâmetros obtidos a partir de mediçóes no próprio lisímetro e de análises de amostras sólidas em laboratório.

As Figuras 3 a 7 mostram alguns parâmetros monitorados no lisímetro. Estes parâmetros estão correlacionados entre si uma vez que podem oferecer uma visão da evolução do processo biodegradativo ao longo do tempo e em profundidade.

A temperatura no interior do lisímetro teve um comportamento bastante interessante. No início das mediçóes em agosto de 2004 manteve-se alta a aproximadamente $1,60 \mathrm{~m}$ de profundidade (atingindo $40^{\circ} \mathrm{C}$ ) e posteriormente nos meses de setembro e outubro de 2004 ocorreu um decréscimo de maneira acentuada, inclusive atingindo os menores valores medidos $\left(25^{\circ} \mathrm{C}\right)$. Entretanto, nos meses subseqüentes ocorreram aumentos graduais de temperatura, contudo não atingindo os valores inicialmente medidos. $\mathrm{Na}$ fase inicial após a disposição dos resíduos no lisímetro o aumento elevado da temperatura já era esperado. Este aumento provavelmente está relacionado a microrganismos aeróbios que ao degradarem a matéria orgânica a compostos mais simples como $\mathrm{H}_{2} \mathrm{O}$ e $\mathrm{CO}_{2}$ liberam calor, pois o processo é exotérmico. Ao longo do tempo o oxigênio do meio é consumido rapidamente e os grupos predominantemente aeróbios dão lugar a organismos anaeróbios. Contudo esta mudança de fase ocorre de forma brusca e estes novos grupos microbianos têm que se adaptar enzimaticamente a este meio. Nesta mudança de fase há um decréscimo na temperatura devido aos microrganismos anaeróbios gerarem menos calor durante o processo de degradação. Portanto pode-se relacionar o decréscimo de temperatura conforme mostra a Figura 3 com a presença crescente de microrganismos anaeróbios (Figuras 4 e 5).

Durante as mudança de grupos degradativos a atividade metabólica (consumo de matéria orgânica) é menor, portanto as temperaturas do meio ficam reduzidas. Isto pode explicar porque a temperatura do meio caiu excessivamente após o primeiro mês do enchimento. A Figura 4 mostra com clareza que os grupos microbianos têm um comportamento de sucessão, ou seja, os microrganismos aeróbios decrescem enquanto os microrganismos anaeróbios aumentam em número. A Figura 4 mostra ainda que com o passar do tempo os organismos anaeróbios passam de valores em torno de NMP de 108 para 1012, principalmente na faixa inferior do lisímetro.

Ressalta-se ainda que a temperatura após o estágio inicial voltou a subir, mas de maneira gradual e isto é justificado pelo crescente aumento dos grupos anaeróbios. Estes organismos estão numa atividade mesotérmica o que também foi verificado em trabalhos com células experimentais por Junqueira $(2000)$.

Deve-se ressaltar que as temperaturas medidas pelos termopares (Figura 1) no lisímetro podem sofrer variações no centro e nas laterais. isto pode ocorrer devido a possíveis trocas de calor do meio interno com o externo, caracterizando o efeito parede. Entretanto, mais estudos devem ser efetivados a fim de entender melhor como se processa tal efeito e quais as suas relações com a microbiologia e recalques.

As Figuras 4 e 5 mostram que no lisímetro há uma grande quantidade de microrganismos de diferentes espécies. Isto é muito importante, pois quanto maior a diversidade de microrganismos, maior será a possibilidade de degradação da matéria orgânica ali existente.

Os microrganismos amilolíticos, proteolíticos e celulolíticos mostram a grande variedade de grupos microbianos presentes na massa de lixo, responsáveis pela degradação da matéria orgânica. Neste ambiente os organismos fazem simbiose, uma vez que, os produtos sintetizados por um grupo servirão de substrato para o outro grupo e desta forma ocorre uma sucessão de espécies trabalhando para a degradação completa da matéria orgânica.
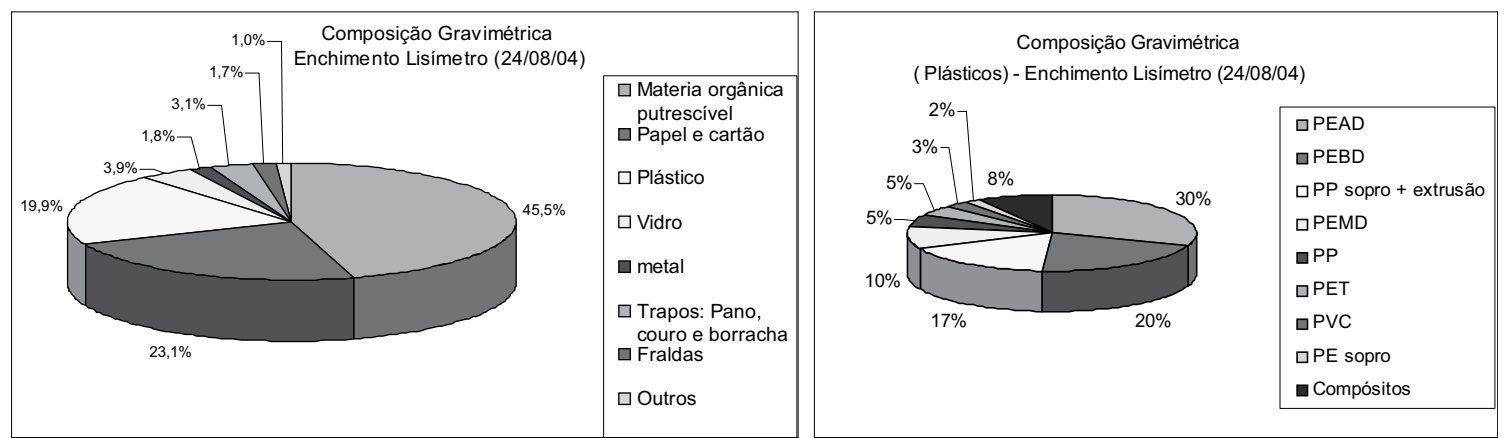

Figura 2 - Composição gravimétrica dos resíduos utilizados no preenchimento do lisímetro 


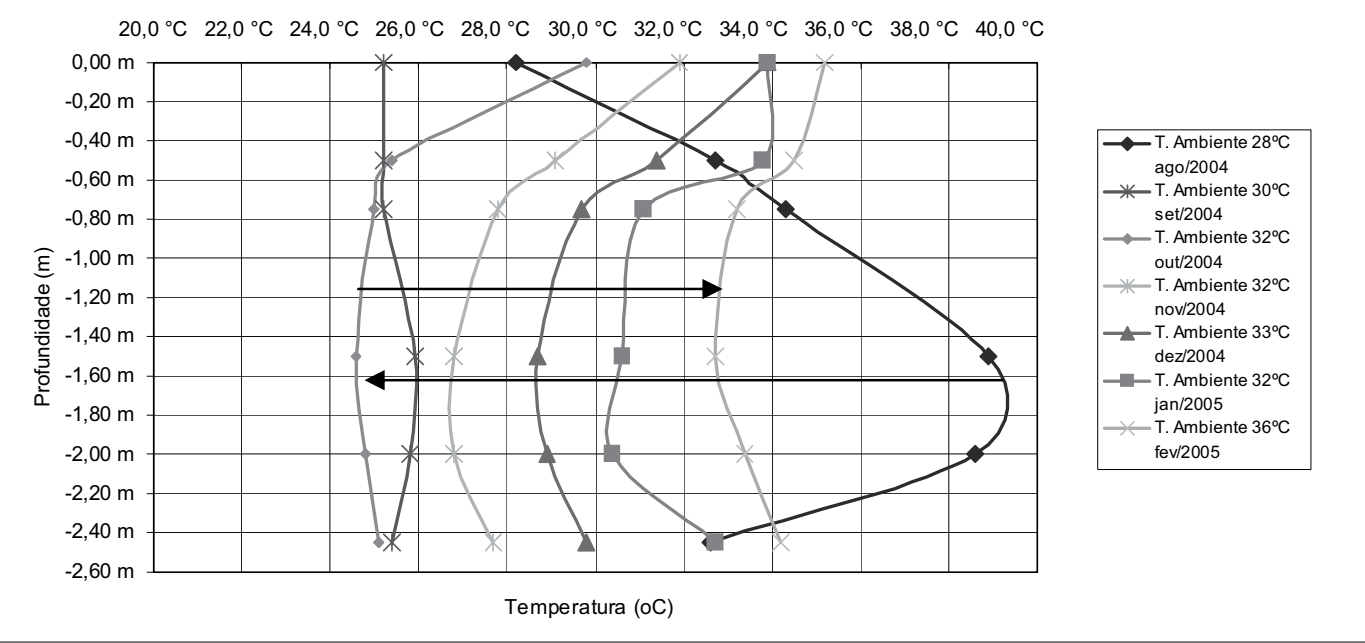

Figura 3 - Temperaturas medidas no lisímetro

É importante frisar que os microrganismos celulolíticos são de extrema importância para o desenvolvimento da degradação. Devido a estes microrganismos há uma seqüência dos seguintes passos metabólicos. Estes organismos degradam a celulose, material de difícil degradação por outros microrganismos, e liberam a glicose que agora pode ser consumida pelos outros grupos de microrganismos, já que a glicose é mais facilmente metabolizada.

Outro fator importante é permitir o desenvolvimento de fungos, já que estes organismos degradam a celulose. Estudos importantes sugerem que algumas espécies de fungos se desenvolvem tanto em ambientes aeróbios como anaeróbios (Melo et al, 2005-artigo não publicado). Portanto, estudar e quantificar estes organismos são de suma importância, pois eles podem favorecer os passos seguintes da degradação da matéria orgânica. No lisímetro foram encontrados fungos (NNP na faixa de $10^{3} \mathrm{a} 10^{5}$ ) tanto na parte superior (ambiente mais aeróbio) como na inferior (ambiente mais anaeróbio). Estudos desenvolvidos por Melo (2003) e Monteiro (2003) também foram encontrados fungos em profundidades bastante elevadas no Aterro da Muribeca.

As Figuras 4 e 5 mostram o comportamento dos microrganismos aeróbios e anaeróbios no interior do lisímetro nas faixas superior e inferior. $\mathrm{Na}$ Figura 4 os aeróbios e anaeróbios totais, como já descrito, têm um comportamento interligado, mas inversos, ou seja, enquanto o grupo dos aeróbios totais decresce com o tempo os anaeróbios crescem. Nas faixas inferior e superior do lisímetro não são evidenciadas diferenças significativas entre a contagem de microrganismos aeróbios e anaeróbios totais talvez porque as dimensões da célula experimental sejam reduzidas.

A Figura 5 mostra que os microrganismos anaeróbios celulolíticos apresentaram em relação aos demais grupos estudados (amilolíticos e proteolíticos) um menor NMP. Alves (2005), destaca que tal fato deve-se possivelmente a maior complexidade de degradação da celulose. Segundo Ryckeboer et al, (2003) a biodegradação microbiana direta da celulose é restrita a uma estreita faixa de microrganismos e, além disso, Villas Bôas (1990), afirma que a atuação das bactérias celulolíticas é bastante lenta, seja pela baixa umidade do sistema ou pela complexidade da molécula desse polissacarídeo. Além disso, a biodegradação da celulose é um processo complexo porque em resíduos vegetais a celulose existe junto com lignina, uma molécula de difícil degradação (Chandra\& Rustgi, 1998; Rodriguez et al, 2004) e, segundo Young \& Frazer (1987), a lignina sob condiçôes de anaerobiose é um composto recalcitrante.

Apenas microrganismos, entre eles, protozoários, fungos e bactérias, são capazes de degradar a molécula de celulose por possuírem as enzimas ligninolíticas e celulases. A degradação da celulose é um fator fundamental, pois este polissacarídeo é um importante constituinte dos resíduos municipais (Pouncelot \& Day, 1973; Lynch, 1987) sendo considerado, então, um dos passos limitantes no processo biológico que ocorre nos aterros de RSU (Rodriguez et al, 2004).

Os organismos proteolíticos tiveram contagens maiores em relação aos amilolíticos e celulolíticos. Isto pode ser justificado, uma vez que as moléculas de proteínas são mais fáceis de serem degradadas se comparadas às moléculas de amido e celulose, portanto estão sendo consumidas mais rapidamente e conseqüentemente o NMP de proteolíticos é mais elevado.

Dados de umidade também tiveram um comportamento bastante típico. A umidade média do lixo no lisímetro, durante os seis meses de monitoramento, apresentou valores sempre crescentes e numa faixa de $25 \%$ a $45 \%$, que pode ser considerada dentro da faixa satisfatória para a biodegradação (Palmisano \& Barlaz, 1996). Observa-se que durante o enchimento do lisímetro, que durou três dias, houve uma perda considerável de água uma vez que houve exposição da massa de lixo ao ambiente. A umidade do lixo na caracterização inicial era aproximadamente de $52 \%$, um valor dentro da normalidade para as condições brasileiras reduzindo para um valor de $25 \%$ após um mês do fechamento do lisímetro. Entretanto esta umidade vem crescendo com o tempo, provavelmente devido à infiltração de líquidos pela camada de cobertura e a degradação do lixo com conseqüente geração de umidade. Os dados de só- 

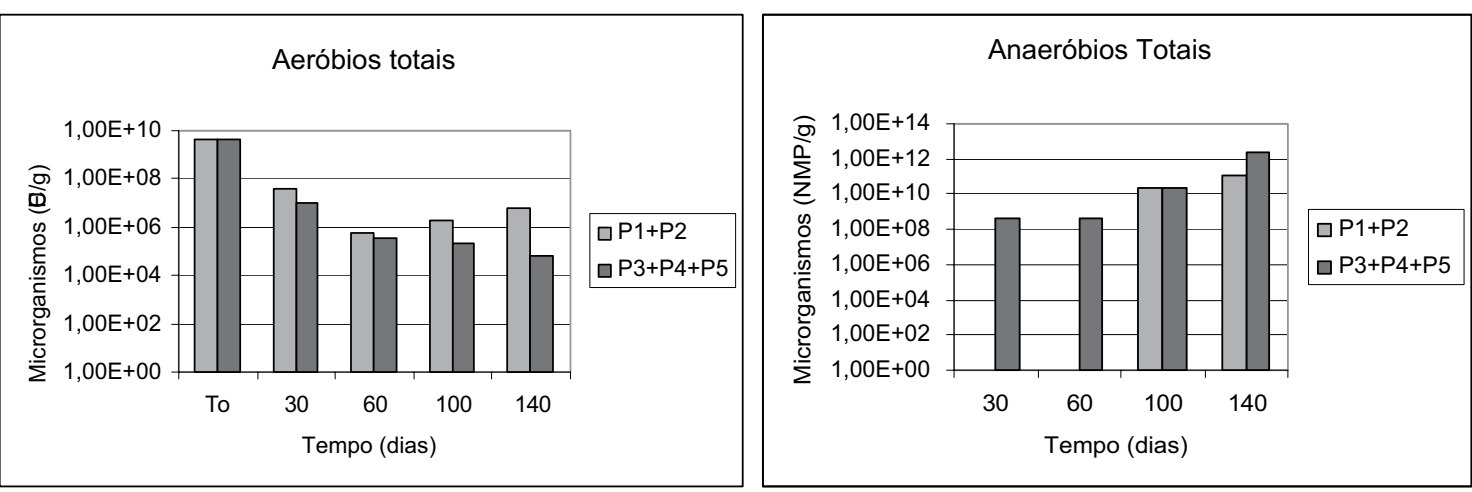

Figura 4 - Microrganismos aeróbios e anaeróbios totais
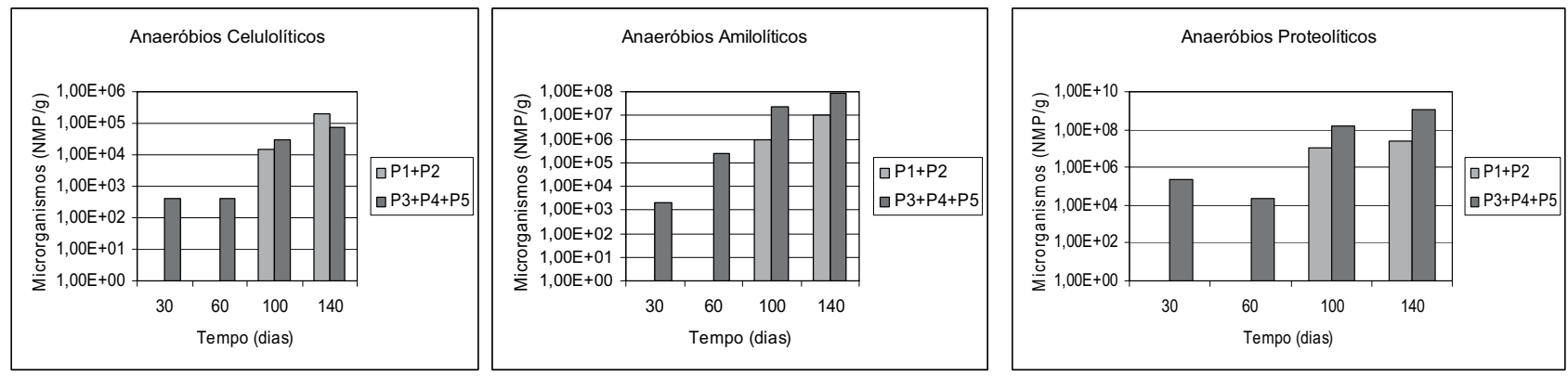

Figura 5 - Microrganismos anaeróbios celulolíticos, amilolíticos e proteolíticos

lidos voláteis mostram um decréscimo com o tempo sendo compatível com a evolução do processo degradativo da matéria orgânica.

$\mathrm{O}$ pH médio de amostras do lixo coletadas até janeiro de 2005 variou entre 6,3 a 5,6 indicando uma fase ácida. Esses resultados estão de acordo com Palmisano \& Barlaz (1996) que cita dados de $\mathrm{pH}$ de lixo na fase anaeróbia ácida numa faixa de 5,7 a 6,2. Os dados do monitoramento de gás indicam uma concentração volumétrica de $\mathrm{CO} 2$, $\mathrm{CH} 4, \mathrm{e} \mathrm{O} 2$, respectivamente, da ordem de $33 \%, 10 \%$ e $0,8 \%$ e são compatíveis com a fase III (ácida) na qual a geração de gases em aterros é a que antecede a fase de fermentação metanogênica (Tchobanoglous et al 1993).

As Fiuras 6 e 7 mostram o comportamento do recalque com o tempo e sua relação com a microbiologia. As deformações que a massa de lixo apresentou foram expressivas e da ordem de 9\% (superficial) e $8 \%$ (em profundidade) para o disco magnético e $7,6 \%$ para as placas superficiais. Observa-se ainda que os recalques superficiais medidos pelas duas metodologias tiveram comportamento semelhantes, entretanto as placas apresentaram valores um pouco menores, o que é justificável, pois possuem uma área bem maior que a dos discos e, portanto, sofrem menos influência de variaçôes locais na densidade do lixo.

Os recalques mostrados apresentam um comportamento semelhante ao estudado por Melo (2003) em uma célula do aterro da Muribeca. Semelhantemente aos resultados apresentados por esse mesmo autor os recalques ocorridos no lisímetro tiveram o seguinte comportamento: recalques sucessivos e bruscos seguidos de recalques zeros. Segundo Melo (2003) e McDougall et al (2004) esses recalques podem ser explicados por períodos de intensa atividades metabólicas com aumento dos vazios do lixo. Esses vazios permanecem até um determinado ponto, ou seja, até suportarem as cargas impostas, então acontece $o$ recalque, pois ocorre a liberação de líquidos e gases oriundos da própria degradação microbiana.

Fazer uma ligação entre a quantidade de microrganismos degradadores de matéria orgânica com a magnitude e velocidade dos recalques é bastante interessante. Pode-se dizer que há uma correlação estreita entre essas grandezas, pois, à medida que um parâmetro varia, os demais obedecem a mesma relação. No caso específico do lisímetro a Figura 7 mostra que, com o passar do tempo, tem-se uma diminuição nos valores de recalques e uma elevação nos valores de NMP de organismos anaeróbios e ainda um decréscimo de organismos aeróbios. Inicialmente o recalque imediato verificado deve-se principalmente às cargas impostas do próprio lixo. Passado este primeiro momento os recalques decrescem, pois a partir dessa fase estes recalques serão originados principalmente devido à degradação microbiana somado às cargas do próprio lixo. No caso específico do lisímetro os NMPs dos aeróbios decresceram na faixa inferior e os anaeróbios elevaram-se e este comportamento é o esperado, contudo na atual fase do monitoramento é ainda precoce correlacionar estes resultados com os recalques, não que estes estejam conflitantes, mas porque as medições caracterizam as fases iniciais dos processos que ocorrem no interior do lisímetro. Entretanto a Figura 7 é bastante ilustrativa, pois mostra de maneira adequada a inversão dos grupos microbianos acompanhados dos recalques.

\section{CONCLUSÕES}

O estudo desenvolvido na célula experimental no Aterro da Muribeca teve as seguintes conclusōes:

- O comportamento dos resíduos no lisímetro foi determinado por aspectos mecânicos, degradativos e climáticos. Até o período monitorado 


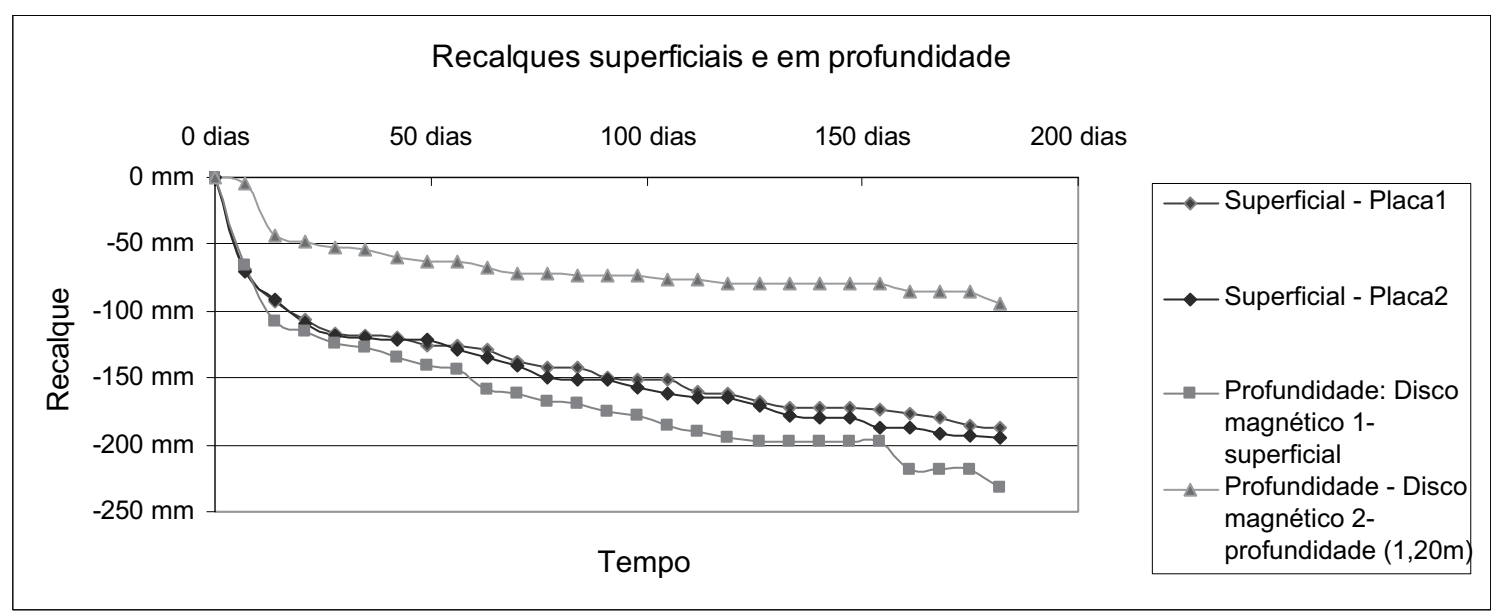

Figura 6 - Evolução dos recalques com o tempo

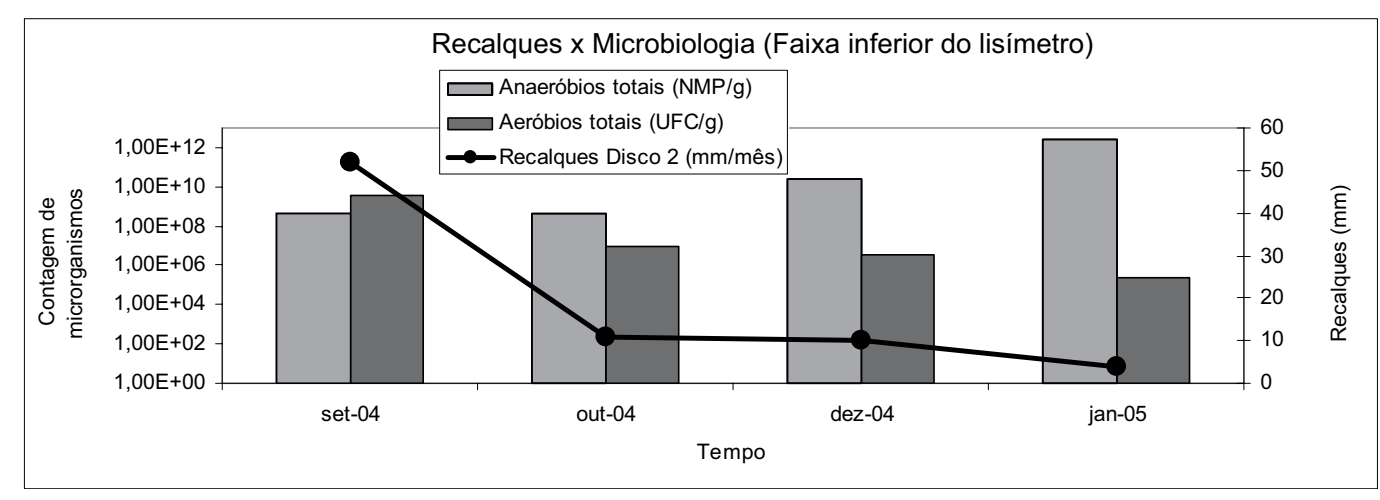

Figura 7 - Recalques versus microbiologia com o tempo

as fases de degradação dos resíduos foram características: fases aeróbia e anaeróbia (hidrólise e acidogênica e acetogênica) sendo representada através de parâmetros como $\mathrm{pH}$, sólidos voláteis, temperatura, microrganismos e recalques.

- A temperatura no interior do lisímetro teve um comportamento característico de cada fase degradativa. Inicialmente, mantendo-se alta, típica de ambiente aeróbio e decaindo com o passar do tempo à medida que se estabelecia um ambiente anaeróbio.

- Nota-se a inversão dos grupos microbianos, ou seja, os microrganismos aeróbios decrescem enquanto os microrganismos anaeróbios aumentam em número o que justifica a mudança de fase com a evolução do processo.

- Fazer uma ligação entre a quantidade de microrganismos degradadores de matéria orgânica com a magnitude e velocidade dos recalques é bastante interessante. Pode-se dizer que há uma correlação estreita entre essas grandezas, pois, à medida que um parâmetro varia, os demais obedecem a mesma relação. Ao longo do tempo, tem-se uma di- minuição nos valores de recalques e uma elevação nos valores de NMP de organismos anaeróbios e ainda um decréscimo de organismos aeróbios.

- Os recalques que a massa de lixo apresentaram foram expressivos e uma nova abordagem foi concebida para explicá-lo. Inicialmente o recalque imediato verificado deve-se principalmente as cargas impostas do próprio lixo. Passado este primeiro momento os recalques são originados principalmente devido à degradação microbiana somado as cargas do próprio lixo. Entretanto não se pode entender este processo separadamente, pois ambos são dependentes. As deformaçôes verticais em resíduos são possíveis pela formação de vazios, produto da biodegradação, tais vazios são desfeitos pelas cargas impostas permitindo a expulsão de líquidos e gases, portanto está seqüência tem que ser seguida.

- Os recalques mostrados no lisímetro foram sucessivos e bruscos seguidos de recalques zeros. Estes recalques são explicados por períodos de intensa atividade metabólica com aumento dos vazios do lixo. Esses vazios permanecem até um determinado ponto, ou seja, até suportarem as cargas impostas, então acontece o recalque.

\section{AGRADECIMENTOS}

Ao PROSAB/FINEP, PRONEX/ CNPq/FACEPE e EMLURB/ATEPE pelo suporte financeiro para o desenvolvimento deste trabalho.

\section{REFERÊNCIAS}

ALVES, I.;R.;F;S. Avaliação da população microbiana dos resíduos sólidos de um lisimetro no aterro da Muribeca-PE. Monografia de Bacharelado em Ciências Biológicas. Universidade Federal de Pernambuco. Recife-PE, 2005.

APHA, AWWA, WPFC. Standard Methods for the Examination of Water and Wastewater. 21 $1^{\mathrm{a}} \mathrm{ed}$. Washington. D. C. pp.1268, 2002.

BORGLIN, S. E. et al. Comparison of Aerobic and Anaerobic Biotreatment of Municipal Solid Waste. J. Air \& Waste Manage. Assoc. V. 54, p. 815-822, 2004.

CETESB. Resíduos Domésticos: tratamento. São Paulo-SP, 1990.

CHANDRA, R. \& RUSTGI, R. Biodegradable Polymers. Progess in polymer science. Great Britain. v 23. pp 1273-1335, 1998. 
FOOD AND DRUG ADMINISTRATION. Bacteriological Analytical Manual. 6 ed. Estados Unidos, 1984

IPT/CEMPRE. Lixo Municipal: manual de gerenciamento integrado. ISBN 85-09-00106-5, 2000.

JUNQUEIRA, F. F. Análise do Comportamento de Residuos Urbanos e Sistemas Dreno Filtrantes em Diferentes Escalas, com Referência ao Aterro do Jóquei Clube - DF Tese de Doutorado. Universidade de Brasília. pp. 283, Brasília, DF, 2000.

MCDOUGALL, J.R. et al. Decomposition and settlement in landfilled waste and other soil-like materials. Geotéchnique 54. № 9. 605-610. ICE. UK. ISSN 0016-8505, 2004.

MELO, M.C. Uma Análise de Recalques Associada a Biodegradação no Aterro de Resíduos Sólidos da Muribeca. Dissertação de Mestrado. Universidade Federal de Pernambuco (UFPE). Recife-PE, pp.1127, 2003.

MELO, M.C., DILON, A.P.J. MONTEIRO, V.E.D. Fungos: importantes decompositores presentes na massa de lixo. Artigo não publicado, 2005.

MONTEIRO, V.E.D. Análises fisicas, químicas e biológicas no estudo do comportamento do aterro da Muribeca. Tese de Doutorado. Universidade Federa de Pernambuco, Recife, PE. pp. 1-232, 2003.

PALMISANO, A.C. \& BARLAZ, M.A. Microbiology of Solid Waste. In: Anna C. Palmisano, Morton A. Barlaz (eds). pp.1-224, 1996.
PALMISANO, A.C.; MARUSCIK, D.A.; Schwab, B.S. Enumeration of fermentative and hydrolytic micro-organisms from three sanitary landfills. Journal of General Microbiology, Vol. 139, pp. 387-391, 1993.

POINCELOT, R. P.; DAY, P.R. Rates of cellulose decomposition during the compost of leaves combined with several municipal and industrial wastes and other additives. Compost science. London. v 14, pp 23-25, 1973.

RODRIGUEZ, C. et al. Development of an enzymatic assay for the determation of cellulose biovailability in municipal solid waste. Biodegradation. Netherlands. v 00. p.1- 8, 2004.

RYCKEBOER, J. et al. Microbiological aspects of biowaste during composting in a monitored compost bin. Journal of applied microbiology. U.K. v 94. pp. 127 - 137. 2003.

TCHOBANOGLOUS, G.; THEISEN, H. \& VINIL, S. Integrated solid waste management Engineering principles and management issues. Irwin MacGraw-Hill, 1993.

VILLAS BÔAS, D.M. F. Estudo da microbiota anaeróbia hidrolitica-fermentativa em aterros sanitários. Dissertação de Mestrado - Escola de Engenharia de São Carlos - SP. pp.156, 1990.

YOUNG, L.Y., FRAZER, A.C.. The fate of lignin and lignin derived compounds in anaerobic digestion enviromenments. Geomicrobiology journal. New York. v.05. pp. 261 - 293, 1987.

WHO - International Reference Center for Wastes Disposal. Methods of analysis of sewage sludge solid wastes and compost. Switzerland, 1979.

Endereço para correspondência:

Veruschka Escarião Dessoles

Monteiro

Departamento de Engenharia

Civil

Universidade Federal de Campina

Grande

Av. Aprígio Veloso, 882 - Bodocongó 58 1 09-970 Campina Grande - PB

- Brasil

Tel.: (83) 3310-1069 Ramal 23

E-mail: veruschkamonteiro@ hotmail.com 